\title{
In vitro Release Kinetic Study of Theophylline from Kollidon SR Polymer Based Matrix Tablet
}

\author{
Abul Kalam Lutful Kabir, Shimul Halder and Abu Shara Shamsur Rouf
}

Department of Pharmaceutical Technology, University of Dhaka, Dhaka-1000, Bangladesh

Received: August 07, 2014; Accepted: March 09, 2015; Published (web): March 12, 2015

\begin{abstract}
Controlled release tablet matrix of theophylline was prepared with kollidon SR, a spray dried powder grade polymer (polyvinyl acetate and povidone based matrix rate retarding hydrophobic materials) by utilizing direct compression technique. Different proportion of kollidon SR was used to develop the matrix builder in the five proposed formulations (F-1 to F-5) for the study of release rate retardant effect at 10, 12, 15, 18 and 21\% of total weight of matrix tablet, respectively. The in vitro dissolution study of the matrices of those proposed tablet formulations were carried out in simulated gastric medium $(\mathrm{pH}$ 1.3) for first two hours and then in simulated intestinal medium (pH 6.8) for 6 hours using USP dissolution apparatus II (paddle method). The formulation F-3 (using 15\% polymer) and F-4 (using $18 \%$ polymer) met the optimum release profiles of active ingredient for $8 \mathrm{hr}$ period of total study. The release kinetics for theophylline was plotted against zero order, first order and Higuchi release rate kinetics to evaluate the release mechanism of drug from the formulated tablet matrix. The release kinetics of formulation F-3 and F-4 was followed very closely by Higuchi release rate kinetic order than other kinetics such as zero order and first order kinetics which has been reflected the type of drug release from the tablet matrix by diffusion as well as erosion mechanism.
\end{abstract}

Key words: Theophylline, direct compression, controlled release/sustained release, kollidon SR, tablet matrix

\section{INTRODUCTION}

Theophylline, a naturally occurring alkaloid is one of the most widely prescribed drugs for the treatment of airway diseases worldwide, where the major use is in the treatment of asthma and chronic obstructive pulmonary disease (COPD). According to recent international guidelines, theophylline has been relegated to third-line therapy in asthma (Global Initiative for Asthma Guidelines 2002) and COPD. ${ }^{1}$ In this study theophylline sustained release tablet matrix was prepared by direct compression method by utilizing kollidon SR polymer. These polymers are hydrophobic in nature and can hold active ingredients firmly that depends on the concentration or ratio of the polymers used. ${ }^{2}$ Oral sustained release dosage form by direct compression technique is a very simple approach of drug delivery system that proved rational demand in the pharmaceutical arena because

Correspondence to: Abul Kalam Lutful Kabir E-mail: aklkabir@gmail.com

Dhaka Univ. J. Pharm. Sci. 14(1): 43-48, 2015 (June) of its ease, compliance and faster production. It also avoids hydrolytic or oxidative reactions during processing of dosage forms. Sustained or controlled drug delivery occurs while embedded with a polymer that may be natural or semi-synthetic or synthetic in nature. The polymer is judiciously combined with the drug or other active ingredients in such a way that the active ingredient is released from the materials in a redesigned fashion and released the drug at constant rate for desired time period. ${ }^{3}$ There are a number of techniques applied in the formulation as well as in the manufacturing of sustained release dosage forms. However, the matrix tablet by direct compression has attracted much more attention due to its technological simplicity in comparison to other controlled release delivery systems. Direct compression method has been applied for preparation of tablet matrix that was involved simple blending of all ingredients used in the formulations and then under went direct compression. It required fewer unit operations, less machinery; reduced number of personnel and short 
processing time, increased product stability and faster production rate. ${ }^{4} \mathrm{~A}$ wide array of polymers has been employed as drug retarding agents each of which presents a different approach to the matrix concept. Polymers that primarily form insoluble or skeleton matrices are considered as the first category of retarding materials and are classified as plastic matrix systems. The second class represents hydrophobic and water-insoluble materials, which are potentially erodable and the third group behaves hydrophilic properties. ${ }^{5}$ There are three primary mechanisms by which active agents can be released from a delivery system: diffusion, degradation, and swelling followed by diffusion. The release of drug from the tablet matrix depends on the nature of polymer. kollidon SR is hydrophobic polymer that becomes hydrated, swollen and facilitates to diffuse the drug. In the present study an attempt has been made to formulate theophylline sustained release tablet matrix with the addition of release retarding agent kollidon SR and to evaluate its effect to sustain the release of theophylline from the tablet matrix and determine the type of polymer which exhibit better sustained release of theophylline. ${ }^{6}$

\section{MATERIALS AND METHODS}

Materials. Theophylline (Merk, Germany), kollidon SR (BASF, Germany), microcystalline cellulose (Avicel-101) (Hanau Chemicals Ltd., Japan), polyvinnyl pyrrolidone (Povidone K-30) (Hanau Chemicals Ltd., Japan), colloidal anhydrous silica (Aerosil 200) (Hanau Chemicals Ltd., Japan), magnesium stearate (Hanau Chemicals Ltd., Japan), hydrochloric acid (Merk, Germany), sodium hydroxide (Merck, Germany) and ortho phosphoric acid (Merk, Germany) were used.

Equipments: Single punch tablet press, Simadzu UV spectophometer, digital $\mathrm{pH}$ meter, electronic hardness tester (Ereweka, Germany), electrolab tablet dissolution test machine (XXII), Sartorius electronic balance.

Preparation of dissolution medium. For dissolution simulated gastric-media $(\mathrm{pH}$ 1.3) and intestinal-media $\quad(\mathrm{pH} \quad 6.8)$ were required.
Preparation of gastric medium $(0.1 \mathrm{~N}$ HCl pH 1.3): For $0.1 \mathrm{~N} \mathrm{HCl}, 11.4 \mathrm{ml}$ of hydrochloric acid $(32 \% \mathrm{w} / \mathrm{v})$ was diluted with sufficient water to produce $1000 \mathrm{ml}$.

Preparation of intestinal medium (buffer pH 6.8): $20 \mathrm{ml}$ sodium hydroxide (25\%) was diluted with 0.1 $\mathrm{N}$ hydrochloric acid to $1000 \mathrm{ml}$ and the $\mathrm{pH}$ was adjusted to 6.8 by addition of $1.2 \mathrm{ml}$ of orthophosphoric acid.

Preparation of matrix tablet. Drug, polymer and other necessary excipients were weighed separately for 20 tablets per formulation as per the proposed method (coded as F-1, F-2, F-3, F-4, and F-5). The amounts of drug and excipients are expressed in milligram. Then active ingredient, microcrystalline cellulose, povidone K-30, polymer and aerosil were blended for 15 minutes and then magnesium stearate was added and further blended for another 1 minute. Blended mass was taken in the hopper and then die and punch were adjusted to get the desired weight of the tablet (500 mg). The tablets were prepared by direct compression using kollidon SR (Table-1), the tablets were weighed and tablet weight was found within $495 \mathrm{mg}$ to $505 \mathrm{mg}$.

Hardness and friability. For each formulation, the hardness and friability of 6 tablets were determined using the Monsanto hardness tester and the Roche friabilator respectively. ${ }^{7-9}$

Thickness. The thickness of the tablets was determined using a thickness gauge. Five tablets from each batch were used and average values were calculated. $^{7-9}$

Weight variation test. To study weight variation, 20 tablets from each formulation were weighed using an electronic balance and the test was performed according to the official method. ${ }^{7-9}$

In vitro release kinetics study. Dissolution studies were conducted according to USP method (USP XXII) using apparatus II (paddle apparatus) at a speed of $100 \mathrm{rpm}$ and the temperature was maintained at $37.0 \pm 0.5{ }^{\circ} \mathrm{C}$. The total duration of dissolution was 8 hours in which for the first 2 hours the tablet matrices were subjected to simulated gastric medium $(0.1 \mathrm{~N} \mathrm{HCl} \mathrm{pH} \mathrm{1.3)} \mathrm{and} \mathrm{the} \mathrm{later} 6$ 
hours to simulated intestinal medium (buffer $\mathrm{pH}$ 6.8).

Acid stage: $900 \mathrm{ml}$ of $0.1 \mathrm{~N} \mathrm{HCl}$ was placed in each vessel and the apparatus was assembled. 6 tablets from each formulation were weighed and placed in the baskets. The operation in the acid stage was carried out for 2 hours. After each hour $10 \mathrm{ml}$ of sample solution was withdrawn and filtered and the volume was adjusted with simulated gastric medium (0.1 $\mathrm{N} \mathrm{HCl}, \mathrm{pH} 1.3)$. The released drug was assayed by using UV spectrophotometer at $272 \mathrm{~nm}$.

Buffer stage: After 2 hours operation in the acid stage, $20 \mathrm{ml} \mathrm{NaOH} \mathrm{(25 \% )} \mathrm{was} \mathrm{added} \mathrm{to} \mathrm{the} \mathrm{previous}$ fluid. The pH $(6.8 \pm 0.05)$ was adjusted with addition of $1.2 \mathrm{ml}$ ortho-phosphoric acid. The operation was continued for 6 hours. After each one hour interval $10 \mathrm{ml}$ of dissolution medium was sampled and filtered and the released drug was assayed by using UV spectrophotometer at $272 \mathrm{~nm}$. At each withdrawal $10 \mathrm{ml}$ of fresh dissolution medium $(\mathrm{pH}$ $6.8 \pm 0.05$ ) was added.

Kinetic analysis of data. The in vitro drug release kinetic data were tested with the following mathematical model:

Zero order equation. The equation assumes the cumulative amount of drug release $v s$ time. The equation may be as follows ${ }^{10}$ :

$$
C=K_{0} t
$$

Where, $K_{0}$ is the zero order rate constant expressed in unit concentration/time and $t$ is the time in hour. A graph of concentration vs time would yield a straight line with a slope equal to $K_{0}$ and intercept the origin of the axes.

First order equation. The release behavior of first order equation expressed log cumulative percentage of drug remaining $v s$ time by using the following equation ${ }^{11}$ :

$$
\log C=\log C_{0^{-}} k t / 2.303
$$

Where, $C$ is the amount of drug undissolved at $\mathrm{t}$ time, the $C_{0}$ is drug concentration at $t=0, k$ is corresponding release rate constant.

Higuchi square root law. The Higuchi release model is described as cumulative percentage of drug release $v s$ square root of time as follows. ${ }^{12}$
$Q=K \sqrt{ } t$

Where, $Q=(100-C)$ the amount of drug dissolved at time $t . K$ is the constant reflecting the design variables of the system. Hence, drug release rate is proportional to the reciprocal of the square root of time.

Different kinetic equations (zero order, first order and higuchi's equation) were applied to interpret the release rate from the tablet matrix. The best fit of higher correlation $\left(R^{2}>0.98\right)$ was found with well-known Higuchi equation.

Higuchi derived the rate of release of drugs dispersed in an inert matrix system as per the following equation -

$$
\mathrm{dM} / \mathrm{dh}=\mathrm{Co} . \mathrm{dh}-\mathrm{Cs} / 2
$$

Where,

$\mathrm{dM}=$ Change in the amount of drug release per unit area

$\mathrm{dh}=$ Change in the thickness of the zone of matrix that been depleted of the drug

Co $=$ Total amount of drug in a unit volume of the matrix

Cs = Sustained concentration of the drug within the matrix

Determination of similarity and dissimilarity factors. Dissolution profiles were compared by fit factors (similarity and dissimilarity factor) using the dissolution profile of reference brand (Nuelin SR). In vitro drug release parameters $\left(\mathrm{R}^{0}=\right.$ rate of input and $t_{\mathrm{del}}=$ time of drug release) of similar release profile (based on $f_{2}$ value) to that of the reference product were fit to in vivo drug concentrations using reported pharmacokinetic properties. Method of superposition was used for steady state prediction of concentration. The values of $C_{\max }$ and $C_{\min }$ obtained by comparing the actual plasma level calculated from clinical trial of those drugs. ${ }^{13,14}$ The goodness of modified release formulations were evaluated from calculated dosage form index,

$$
\mathrm{DI}=C_{\max } / C_{\min }
$$

and fluctuation (\%) $=\left(C_{\max }-C_{\min }\right) \times 100 / C_{\mathrm{av}}----(6)$ 
Where $C_{\max }$ and $C_{\min }$ are maximum and minimum blood concentration, $C_{\mathrm{av}}=$ average blood concentration at steady state.

\section{RESULTS AND DISCUSSION}

In this study kollidon SR (the spray dried powder grade polymer) was used for the development of theophylline sustained release tablet matrix by direct compression method. The effect of kollidon SR on theophylline sustained release dosage form was assessed. As it contains no ionic groups it shows no interaction with most of the commonly used APIs and excipients. ${ }^{15}$ Different percentage of kollidon SR (10, 12, 15, 18 and $20 \%$ of total weight of tablet matrix) containing tablet matrices were added in the dissolution media according to design of study. The percent release from all the respective polymer matrix systems were plotted against time to observe drug release pattern. It was seen that percent of drug release was increased by decreasing the amount of kollidon SR in the proposed formulations (Table 1) and from the release kinetics (Table 2 and 3). The variable ranges of kollidon SR were selected by considering physicochemical behavior of the polymer in the physiological fluid and physicochemical properties of the drug. According to USP, for an ideal sustained release dosage form, the percent release in 1st hour should be not more than $30 \%$ and in $10^{\text {th }}$ hour not less than $80 \%$ (USP $29^{\text {th }}$ Edition, 2006). The release pattern of theophylline from the proposed formulation F-3 (15\% kollidon SR) and proposed formulation F-4 (18\% kollidon SR) met the desired sustained release pattern (Table 3 ). This indicated that at minimum percent i.e. $15 \%$ of kollidon SR met the desired sustained release of theophylline by direct compression method from $1^{\text {st }}$ hour to $8^{\text {th }}$ hour in vitro dissolution studies.

Table 1. Proposed formulations of theophylline matrix tablet.

\begin{tabular}{ccccccccc}
\hline $\begin{array}{c}\text { Formulation } \\
\text { code }\end{array}$ & $\begin{array}{c}\text { Theophylline } \\
(\mathrm{mg})\end{array}$ & $\begin{array}{c}\text { Kollidon } \\
\text { SR }(\mathrm{mg})\end{array}$ & $\begin{array}{c}\text { Avicel } \\
(\mathrm{mg})\end{array}$ & $\begin{array}{c}\text { Povidone } \\
\text { K-30 }(\mathrm{mg})\end{array}$ & $\begin{array}{c}\text { Mg-stearate } \\
(\mathrm{mg})\end{array}$ & $\begin{array}{c}\text { Aerosil } \\
(\mathrm{mg})\end{array}$ & $\begin{array}{c}\text { Total wt. } \\
(\mathrm{mg})\end{array}$ & $\begin{array}{c}\text { Kollidon } \\
\text { SR }(\%)\end{array}$ \\
\hline F-1 & 300 & 50 & 115 & 25 & 5 & 5 & 500 & 10 \\
F-2 & 300 & 60 & 105 & 25 & 5 & 5 & 500 & 12 \\
F-3 & 300 & 75 & 90 & 25 & 5 & 5 & 500 & 15 \\
F-4 & 300 & 90 & 75 & 25 & 5 & 5 & 500 & 18 \\
F-5 & 300 & 100 & 65 & 25 & 5 & 5 & 500 & 20 \\
\hline
\end{tabular}

Table 2. Effect of kollidon SR on theophylline from proposed formulations in gastrointestinal fluid and intestinal fluid.

\begin{tabular}{cccccc}
\hline \multicolumn{7}{c}{ \% Release of drug } \\
\hline Time (hours) & F-1 (10\%) & F-2 (12\%) & F-3 (15\%) & F-4 (18\%) & F-5 (20\%) \\
\hline 0 & 0 & 0 & 0 & 0 & 0 \\
1 & 20.14 & 16.63 & 16.15 & 13.68 & 13.62 \\
2 & 29.09 & 26.13 & 22.63 & 19.6 & 18.15 \\
3 & 53.88 & 48.93 & 43.55 & 37.92 & 33.12 \\
4 & 60.47 & 51.43 & 48.36 & 42.08 & 37.33 \\
5 & 74.69 & 70.68 & 56.32 & 45.88 & 40.16 \\
6 & 80.14 & 73.4 & 65.48 & 49.6 & 48.31 \\
7 & 83.54 & 78.21 & 71.08 & 53.84 & 52.53 \\
8 & 85.26 & 82.32 & 74.25 & 60.21 & 55.14 \\
\hline
\end{tabular}

Table 3. Multiple coefficients of determination data of theophylline matrix tablets.

\begin{tabular}{cccc}
\hline Formulation code & \multicolumn{3}{c}{ Multiple coefficient of determination $\left(\mathrm{R}^{2}\right)$} \\
\cline { 2 - 4 } & Zero order & First order & Higuchi \\
\hline F-1 & 0.92 & 0.91 & 0.96 \\
F-2 & 0.87 & 0.92 & 0.96 \\
F-3 & 0.88 & 0.96 & 0.98 \\
F-4 & 0.89 & 0.95 & 0.98 \\
F-5 & 0.92 & 0.97 & 0.97 \\
\hline
\end{tabular}


Determination of release mechanism from multiple coefficients. The drug release data from the proposed formulations F-1, F-2, F-3, F-4, and F-5 were treated in different kinetic orders such as zero order, first order \& higuchi kinetics and their correlation coefficients were determined graphically to identify their release mechanism (Figures 1 \& 2). The percent drug release was plotted against time to get zero order release kinetics, log\% remaining against time to get first order release kinetics and the percent release versus square root of time to get Higuchi release kinetics. From correlation coefficient the mechanism of release kinetics was determined. When correlation coefficient is close to 1.0, the release kinetics will be following that order of the proposed formulations. From table 3, it was observed that proposed formulations F-3 and F-4 followed Higuchi release mechanism. ${ }^{12}$ Although formulations F-1, F-2, F-3, F-4 and F-5 followed first order and Higuchi release kinetics, the release kinetics was very close to 1 (one) in case of Higuchi plot than other kinetic orders that indicated Higuchi release kinetics was predominant here.

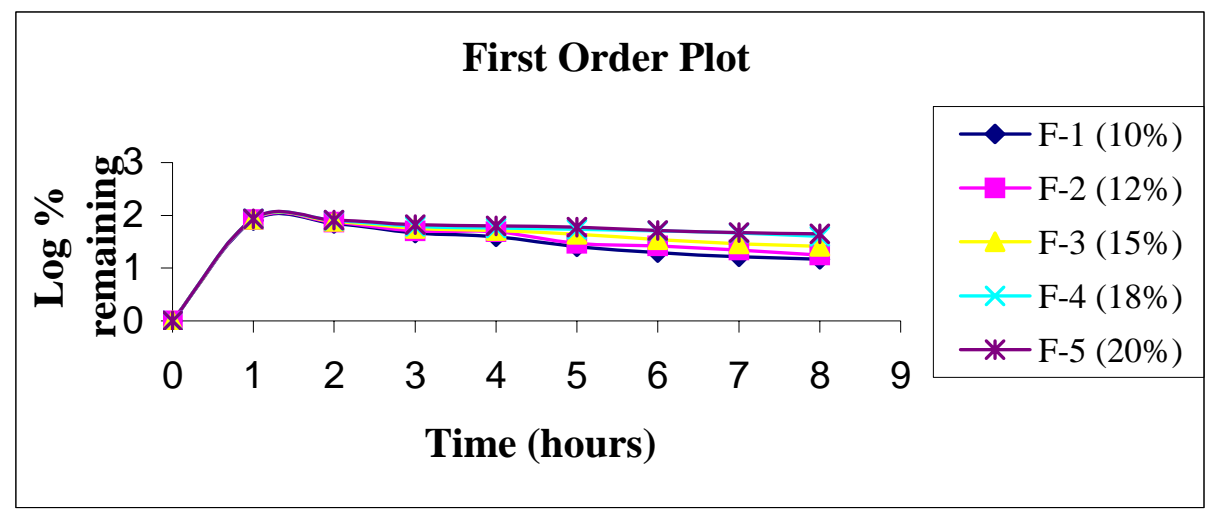

Figure 1. Effect of kollidon SR on theophylline from proposed formulations in gastrointestinal fluid and intestinal fluid (First order plot).

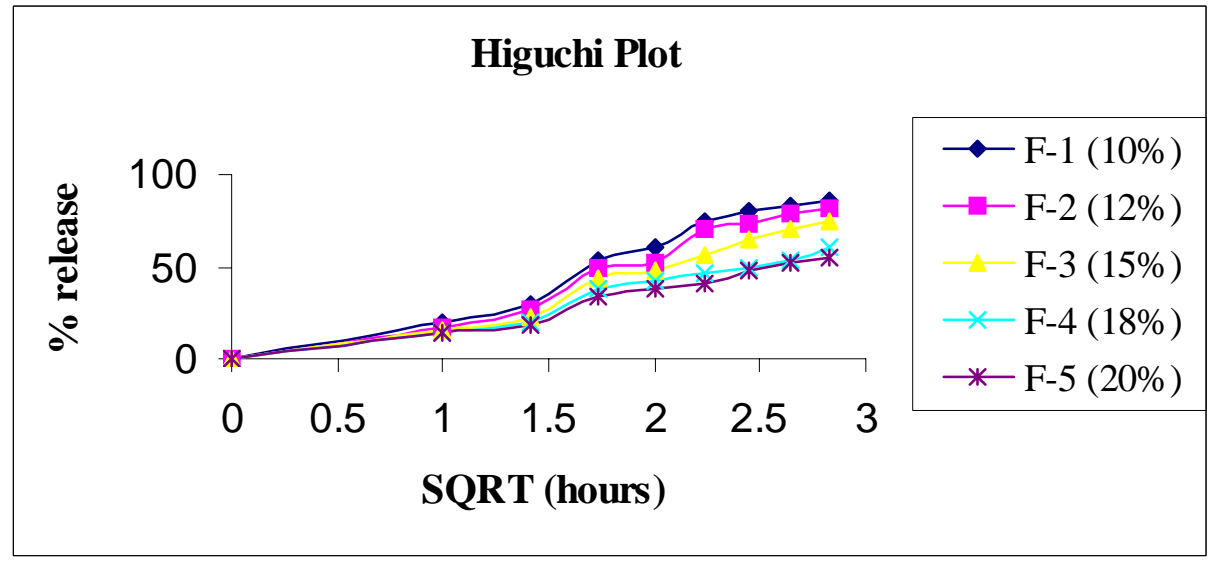

Figure 2. Effect of kollidon SR on theophylline from proposed formulations in gastrointestinal fluid and intestinal fluid (Higuchi plot).

\section{CONCLUSION}

Theophylline is frequently used against some common diseases like asthma and COPD where the patients need to take medications for a long period of time. Sustained release or controlled release dosage forms of theophylline can provide better patient compliance and prolonged action against asthma and COPD. The half life of theophylline is 8 hours in 
adults although there is large intra and inter individual variation, and also varies greatly with age being approximately 30 hours in premature neonates, 12 hours within the first 6 months, 5 hours up to the first year of life and approximately 3.5 hours up to the age of 20 , gradually increasing again thereafter. Due to its rapid elimination and posology, this drug is a suitable candidate to be formulated into sustained release dosage forms. The present study was investigated in order to formulate theophyllinesustained release with addition of release retarding polymer kollidon. ${ }^{16}$ It is concluded from this study that at least $18 \%$ kollidon SR showed the desired sustained release tablet matrix by direct compression. We also observed that Higuchi release kinetics was the predominant release kinetics among all the release kinetics. ${ }^{17}$ The use of direct compression method may increase production performance, save time in manufacturing process and may reduce involvement of labor \& cost and may increase profit. The proposed formulations (F-3 and F-4) may be used for the development of theophylline sustained release matrix and meet the patient's demand in order to combat against asthma and COPD more precisely. However further extensive studies are needed to evaluate in vivo models for the development of the most appropriate theophylline SR formulation.

\section{REFERENCES}

1. British Pharmacopoeia. 2007. The Stationary office on behalf of Medicine and Healthcare Products Regulatory agency, London, 373.

2. Longer, M.A. and Robinson, J.R. 1990. Remington's Pharmaceutical Science. Chapter 91 (Sustained Release Drug Delivery System) (18th Edition), pp. 1676-1690. 1676-1690.

3. Lordi, N.G. 1990. Sustained release dosage forms. In: The Theory and Practice of Industrial Pharmacy. 3rd Edn. (Lachman, L., Lieberman H.A. and Kanig J.L., Eds), Varghese Publishing House, Bombay, pp. 430-456.

4. Shangraw, R.F. 1989. Compressed Tablets by Direct Compression, Pharmaceutical Dosage Forms: Tablets, Lieberman, H.A., Lachman, L. and Schwartz, J.B. (Eds). 1989. (Marcel Dekker, Inc., New York, 2d ed., Volume 1, 1989), p. 219.
5. Reza, S.M., Quadir, M.A. and Haider, S.S. 2003. Comparative evaluation of plastic, hydrophobic and hydrophilic polymers as matrices for controlled-release drug delivery. J. Pharm. Sci. 6, 282-291.

6. Bidah, D. and Vernaud, J.M. 1991. Dosage forms with a polymer matrix and swelling polymer. Int. J. Pharm. 77, 8187.

7. Aulton, M.E. and Wells, T.I. 1998. Pharmaceutics: The science of dosage form sesign. London, England, Churchill Livingstone. pp. 647-649.

8. Liebermann, H.A., Lachman, L. and Schwartz, J.B. 1990. Pharmaceutical dosage forms: Tablets. Marcel Dekker, New York, pp. 201-243.

9. Martin, A. Micromeritics. Ed. 2001. Physical Pharmacy. Baltimore, MD: Lippincott Williams and Wilkins, pp. 423 454.

10. Hadjiioannou, T.P., Christian, G.D. and Koupparis, M.A. 1993. Quantitative Calculation in Pharmaceutical Practice and Research. New York, NY: VCH Publishers Inc; pp. 345348.

11. Bourne, D.W. Pharmacokinetics. In: Banker, G.S. and Rhodes, C.T. eds. 2002. Modern Pharmaceutics. $4^{\text {th }}$ Eds. New York, NY: Marcel Dekker Inc; pp. 67-92.

12. Higuchi, T. 1963. Mechanism of sustained action medication, Theoretical analysis of rate of release of solid drugs dispersed in solid matrices, J. Pharm. Sci. 52, 1145-1149.

13. Lea, A.P. and Mctavish, D. 1997. Atorvastatin: A review of its Pharmacology and therapeutic potential in the management of hyperlipidaemias. Drugs. 53, 828-847.

14. Mauro, V.F. 1993. Clinical pharmacokinetics and practical application of simvastatin. Clin. Pharm. 24, 195-202.

15. Arthur, H.K. 2000. Handbook of Pharmaceutical Excipients. $3^{\text {rd }}$ Edition. American Pharmaceutical Association, Washington, D.C. pp. 252-255

16. Lee, B.J., Ryu, S.G. and Cui, J.H. 1999. Formulation and release characteristics of hydroxypropyl methylcellulose matrix tablet containing melatonin. Drug Dev. Indian Pharm. 25, 493-501.

17. Sungthongjeen, S., Pitaksuteepong, T., Somsiri, A. and Sriamornsak, P. 1999. Studies on pectins as potential hydrogel matrices for controlled-release drug delivery. Drug Dev. Indian Pharm. 25, 1271-1276. 